\title{
Drug Induced Lupus Erythematosus
}

National Cancer Institute

\section{Source}

National Cancer Institute. Drug Induced Lupus Erythematosus. NCI Thesaurus. Code C114354.

An autoimmune disorder, similar to systemic lupus erythematosus, that is caused by certain drugs. 